\title{
Anatomical changes of the styloid process in a Brazilian subpopulation
}

\begin{abstract}
Purpose: The aim of this study was to evaluate the anatomic variations of the styloid process in computed tomography exams, to classify these variations, and investigate their association with patients' sex.
\end{abstract}

Materials and Methods: A total of 171 exams were evaluated, 119 of which were from females and 52 from males. The styloid chain was measure bilaterally and then later classified according to its morphology: normal, elongated, segmented and pseudoarticulated.

Results: Mean styloid process length was $27.6 \mathrm{~mm}(27.9 \mathrm{~mm}$ on the right side and $27.3 \mathrm{~mm}$ on the left), with males showing significantly higher values. As for the frequency of the morphological classification, there was no significant difference for the classification on the right and left side between both sexes.

Conclusion: The most frequent morphological type was "segmented", followed by "normal", "elongated", and the less frequent was "pseudoarticulated".

Keywords: eagle syndrome, tomography, diagnosis
Volume I Issue I - 2014

\section{Rodrigo Steigleder da Costa,' Vania Regina Camargo Fontanella ${ }^{2}$}

'Faculdade of Dentistry, Federal University of Rio Grande do Sul, Brazil

${ }^{2}$ Oral and Maxillofacial Radiology Department, Lutheran University of Brazil and Federal University of Rio Grande do Sul, Brazil

Correspondence: Vania Regina Camargo Fontanella, Oral and Maxillofacial Radiology Department, Lutheran University of Brazil, Canoas, RS, Brazil and Federal University of Rio Grande do Sul, Porto Alegre, RS, Brazil, Graduate Program in Dentistry, Farrukhabad Av 800I, Tel +55-51-34629512,

Email vaniafontanella@terra.com.br

Received: April 13, 2014 | Published: May II, 2014

\section{Introduction}

The styloid process is a cylindrical bony projection that goes throughout the skull base, extending downwards, forwards, and slightly towards the medial side. It lies in front of the stylomastoid foramen, between the internal and external carotid arteries, posterior to the tonsillar fossa, and lateral to the pharyngeal wall. ${ }^{1,2}$ Its normal length is between 2 and $3 \mathrm{~cm}$. When larger than this, the styloid process is considered elongated, which may be associated with Eagle syndrome. ${ }^{2-6}$

In an adult individual, the styloid ligament, which is usually formed by dense fibrous connective tissue, may retain some of its embryonic cartilage and thus has the potential of becoming partially or completely ossified. Thus, if these structures solidify, this may cause pain in some individuals. The mineralization of the styloid complex can be seen quite often, although the prevalence of clinical symptoms ranges from 1 to $5 \%$ in patients with elongated styloid process. ${ }^{7,8}$

As for the variations in the ossification process, the most frequent is the elongation of the styloid process, while the rarest is the complete ossification of the styloid chain. These variations may be associated with some symptoms, such as sore throat, foreign body sensation, pain during swallowing, facial neuralgia, headache, and temporomandibular joint disorders. These symptoms are present in Eagle syndrome and may result from the compression of some nervous and vascular structures around the styloid chain., ${ }^{2,9}$

Radiological exams, such as panoramic radiographs, play an important role in showing these variations, but analyzing conventional imaging can be somewhat difficult due to the overlap of other bone structures. Computed tomography (CT) provides a reliable visualization, leading to an accurate diagnosis. However, only the ossified portions of the styloid chain can be assessed by radiographs, thus describing several variations in the styloid chain, including differences in styloid process length, degrees of angulation, and levels of styloid ligament ossification. ${ }^{9,10}$

The aim of this study was to evaluate, in a Brazilian subpopulation, the anatomical changes of the styloid process in CT exams, to classify these changes, and to investigate their association with patients' sex.

\section{Materials and methods}

This observational cross-sectional study was approved by the Research Ethics Committee of the Universidade Federal do Rio Grande do Sul (record no. 19984). CT scans obtained at the Diagnostic Investigation Service (Service Diagnostic Research, SIDI Ltd.), Porto Alegre, Southern Brazil, in one-year period were retrospectively assessed.

Sample size, calculated based on data by Gozil et al. ${ }^{8}$ and Ramadan et al., ${ }^{9}$ was 160 CT scans. Exams of adult patients that allowed bilateral visualization of the styloid process in its full extent were retrospectively included in the sample. Exams showing anomalies or trauma sequelae were excluded from the study. CT scans were obtained according to the clinic's protocol using the equipment Twin Flash CT Scanner (Elscint, Haifa, Israel) under standardized conditions, with field of view of $250 \mathrm{~mm}$, slice thickness of $1 \mathrm{~mm}$, pitch of $1 \mathrm{~mm}$, matrix of $512 \times 512$, and $120 \mathrm{kVp}$, with variations only in milliamperage, according to patient's bone structure. Scans were recorded in axial plane, and patient's positioning remained constant, with the midsagittal plane aligned to the ground and the palate plane perpendicular to the ground.

Exams were exported on the DICOM format for analysis on Efilm software (Merge, Milwaukee, USA). Based on an axial view, we selected coronal and sagittal images that better represented, on each side, the styloid process in its full extension. The styloid process was measured and subsequently assessed for its morphology. Measurements and assessments were independently performed on right and left sides by an examiner trained and calibrated by an experienced CT professional. The morphology of the styloid process was classified according to the criteria recommended by Langlais et al. ${ }^{11}$ and modified by Guimaraes et al. ${ }^{12}$ (Figure 1 ) into:

1. Normal: The styloid process length may vary, with a mean of 25 $\mathrm{mm}$, or it may be absent. 
2. Elongated: The styloid process and the ligament appear like a continuous structure with more than $2.5 \mathrm{~cm}$ in length.

3. Pseudoarticulated: The styloid process is elongated and seems to be connected with the stylomandibular or the stylohoid ligament by means of a single pseudo-joint, typically located above the mandible angle.

4. Segmented: The elongated styloid process and ligaments consist of several mineralized segments.

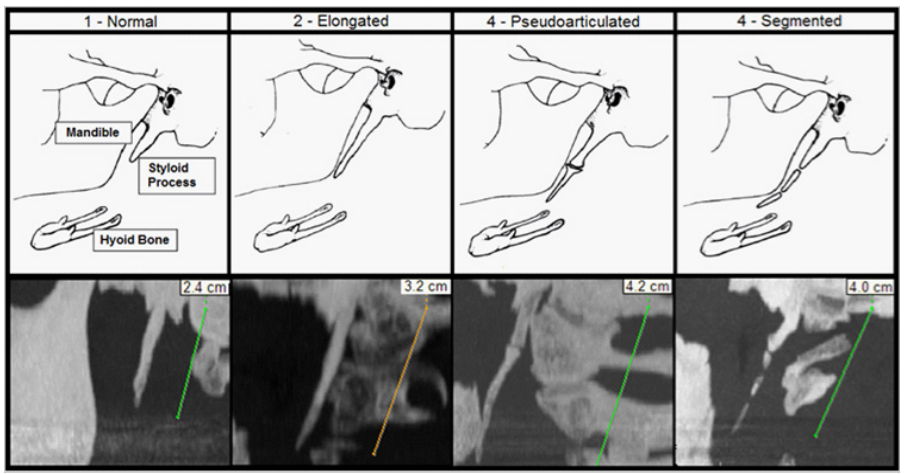

Figure I Upper part: scheme for the morphological classification of styloid process, reproduced from Guimaraes et al. ${ }^{12}$ Lower part: images obtained in this study illustrating morphological classifications.

Data were compiled and expressed using descriptive statistics. The nonparametric Wilcoxon test was used to compare styloid process length between right and left sides. The nonparametric Mann-Whitney test was applied to assess differences in styloid process length between sexes. The chi-square test was applied to investigate a possible association between styloid process morphology and sex on both sides. The nonparametric McNemar test was used to evaluate whether there was significant difference in the classification of right and left sides. For all the above-mentioned tests, the maximum significance level was set at $5 \%(\mathrm{p}<0.05)$, and statistical analysis was performed on SPSS software (SPSS Inc., Chicago, USA), version 10.0.

\section{Results}

A comparison of the linear measurements of the styloid process yielded a mean of $27.9 \mathrm{~mm}$ for the right side and $27.3 \mathrm{~mm}$ for the left side, and the nonparametric Wilcoxon test revealed that there was no significant difference between the two sides in the overall sample. However, when sexes were assessed separately (Table 1), a significant difference was observed between the two sides in females, who presented higher values for the right side $(\mathrm{p}=0.034)$. A comparison of styloid process length between sexes (Table 2) using the nonparametric Mann-Whitney test found a significant difference for both sides, with significantly higher values for males.

Table 3 shows that the most frequent morphology in this sample was "segmented", followed by "normal", "elongated", and "pseudoarticulated", which was the less frequent. Table 4 displays the distribution of the morphological classification of the styloid process according to side and sex. Chi-square test results demonstrated that there was no significant difference in the classification of right and left sides between males and females. An assessment of the overall sample with regard to morphological classification (Table 5) revealed that a statistical test could not be performed, because the sample was not enough for some classifications. When results were dichotomized into normal and altered (the remaining classifications), the results of the McNemar nonparametric test show that there was no significant difference in the classification of right and left sides. There was $81.3 \%$ of agreement between the two sides (Table 6).

Table I Comparison of measures (in $\mathrm{mm}$ ) between right and left sides according to sex. Nonparametric wilcoxon test

\begin{tabular}{lllll}
\hline Comparison & N & Mean & $\begin{array}{l}\text { Standard } \\
\text { Deviation }\end{array}$ & P \\
\hline Females & & & & \\
Right side & 119 & 27.1 & 7.8 & $0.034^{*}$ \\
Left side & 119 & 26.3 & 8.7 & \\
Males & & & & \\
Right side & 52 & 29.9 & 8.9 & 0.810 \\
Left side & 52 & 29.5 & 9.8 & \\
\hline
\end{tabular}

*Significant difference between the two sides for females

Table 2 Comparison of measures (in $\mathrm{mm}$ ) between males and females. Nonparametric Mann-Whitney test

\begin{tabular}{|c|c|c|c|c|}
\hline Sex & $\mathbf{N}$ & Mean & $\begin{array}{l}\text { Standard } \\
\text { Deviation }\end{array}$ & $\mathbf{P}$ \\
\hline \multicolumn{5}{|c|}{ Right Side } \\
\hline Females & 119 & 27.1 & 7.8 & \multirow{2}{*}{$0.040 *$} \\
\hline Males & 52 & 29.9 & 8.9 & \\
\hline \multicolumn{5}{|c|}{ Left Side } \\
\hline Females & 119 & 26.3 & 8.7 & \multirow{2}{*}{$0.006 *$} \\
\hline Males & 52 & 29.5 & 9.8 & \\
\hline
\end{tabular}

*Significant difference between sexes

Table 3 Frequency distribution of the morphological classification of styloid processes according to side

\begin{tabular}{llllll}
\hline \multirow{2}{*}{ Classification } & Overall & \multicolumn{2}{c}{ Right Side } & \multicolumn{2}{c}{ Left Side } \\
& (n) & N & $\%$ & N & $\%$ \\
\hline Normal & 118 & 54 & 31.6 & 64 & 37.4 \\
Elongated & 72 & 40 & 23.4 & 32 & 18.7 \\
Segmented & 124 & 62 & 36.3 & 62 & 36.3 \\
Pseudoarticulated & 28 & 15 & 8.8 & 13 & 7.6 \\
Total & 342 & 171 & 100 & 171 & 100 \\
\hline
\end{tabular}

Table 4 Chi-square Test. Comparison of the morphological classification of styloid process according to side among males and females

\begin{tabular}{lllll}
\hline Variable & Sex & $\begin{array}{l}\text { Sex } \\
\text { Females }\end{array}$ & Males & P \\
\hline $\begin{array}{l}\text { Classification } \\
\text { of the Right }\end{array}$ & Normal & 32.8 & 28.8 & 0.458 \\
Side & Elongated & 20.2 & 30.8 & \\
& Segmented & 38.7 & 30.8 & \\
& Pseudoarticulated & 8.4 & 9.6 & \\
Classification & Normal & 41.2 & 28.8 & 0.461 \\
of the Left & Elongated & 16.8 & 23.1 & \\
Side & Segmented & 34.5 & 40.4 & \\
& Pseudoarticulated & 7.6 & 7.7 & \\
\hline
\end{tabular}


Table 5 Comparison of morphological classification (in percentage) between right and left sides for the total sample

\begin{tabular}{|c|c|c|c|c|c|}
\hline \multirow{2}{*}{$\begin{array}{l}\text { Classification of } \\
\text { the Right Side }\end{array}$} & \multicolumn{5}{|c|}{ Classification of the Left Side } \\
\hline & Normal & Elongated & Segmented & Pseudoarticulated & Total \\
\hline Normal & 25.1 & 2.3 & 2.3 & 1.8 & 31.6 \\
\hline Elongated & 4.7 & 12.9 & 4.1 & 1.8 & 23.4 \\
\hline Segmented & 7.0 & 1.8 & 25.7 & 1.8 & 36.3 \\
\hline Pseudoarticulated & 0.6 & 1.8 & 4.1 & 2.3 & 8.8 \\
\hline Total & 37.4 & 18.7 & 36.3 & 7.6 & 100.0 \\
\hline
\end{tabular}

Table 6 Nonparametric McNemar Test. Comparison of morphological classification (normal or altered) between right and left sides for the overall sample

\begin{tabular}{llll}
\hline \multirow{2}{*}{$\begin{array}{l}\text { Classification of the } \\
\text { right side }\end{array}$} & \multicolumn{2}{l}{ Classification of the Left Side } & \multirow{2}{*}{ Total } \\
\cline { 2 - 3 } & Normal & Altered & 31.6 \\
\hline Normal & $\mathbf{2 5 . 1}$ & 6.4 & 68.4 \\
Altered & 12.3 & $\mathbf{5 6 . 1}$ & 100.0 \\
Total & 37.4 & 62.6 &
\end{tabular}

\section{Discussion}

Morphological changes of the styloid process may be associated with a wide range of symptoms; therefore, its diagnosis is very important and may be achieved by radiographic exams, such as CT, which allows for the measurement of styloid process length and for the assessment of stylohyoid ligament ossification. ${ }^{1,2,6,13}$

Firstly, the present study showed that there was no significant difference between the two sides, which has been already described by Andrade et al. ${ }^{14}$ Mean lengths were $27.9 \pm 8.3 \mathrm{~mm}$ and $27.3 \pm 9.1 \mathrm{~mm}$ for left and right sides, respectively. These values were similar to those found in a previous study that reported a mean value of $27 \mathrm{~mm} .{ }^{9}$

According to the literature, mean styloid process length is usually increased in the male population. ${ }^{8,15}$ In the Ramadan et al. ${ }^{9}$ study, mean styloid process length was $25.5 \mathrm{~mm}$ for women and $28.1 \mathrm{~mm}$ for men. In another recent study, mean styloid process length showed similar values: $22.5 \mathrm{~mm}$ for women and $28.2 \mathrm{~mm}$ for men. ${ }^{16}$ These data are in agreement with the present study, which also found significantly higher values in males.

When right and left sides were compared across sexes, a significant difference between the two sides was observed in women, with the right side showing higher values. No reports were found in the literature mentioning this difference, probably due to the lack of studies. As for the frequency distribution of the different morphological classifications of the styloid process, there was no significant difference in the classification of right and left sides between sexes. The morphological type of each styloid process was assessed based on Langlais et al. ${ }^{11}$ criteria. The segmented pattern was the predominant one, and the pseudoarticulated pattern was the less frequent one. These results differ from previous studies, which observed higher frequency for the elongated morphology. ${ }^{8,12}$ This fact may be explained by the type of diagnostic method used, considering that there may be a difference between the analyses performed in panoramic radiograph and CT, because the latter allows the visualization of the styloid process in its full extent without image overlapping. Additionally, sample was assinged randomly; unlike other studies that evaluated only patients with temporomandibular disorder. ${ }^{12}$ In accordance with Aral et al. ${ }^{16}$ this study did not find a predominance of any side over the other in patients with morphological change of the styloid process.

The normal or altered morphology was symmetric in $81.2 \%$ of the sample. When there was morphological asymmetry between sides, it was observed that in most cases one side was normal and the other was altered. Several studies have been conducted to better understand the functioning of disorders related to temporomandibular joints, whose morphological changes may lead to a number of signs and symptoms that hamper both diagnosis and therapeutic procedures. ${ }^{12,17,18}$ Additionally, most of the studies about morphological changes of the styloid process found in the literature are case reports that evaluate disease symptoms and the presence of styloid process elongation, without evaluating its morphology.

In conclusion, styloid process length ranged from 26.3 to $29.9 \mathrm{~mm}$ in the sample, with males showing higher values. There was significant variation between sides only in the female sample. The most frequent morphological type was "segmented", followed by "normal", "elongated" and "pseudoarticulated".

\section{Acknowledgments}

None.

\section{Conflict of interest}

The author declares that there is no conflict of interest.

\section{References}

1. Yavuz H, Caylakli F, Yildirim T, et al. Angulation of the styloid process in Eagle's syndrome. Eur Arch Otorhinolaryngol. 2008;265(11):1393-1396.

2. Fusco DJ, Asteraki S, Spetzler RF. Eagle's syndrome: embryology, anatomy, and clinical management. Acta Neurochir (Wien). 2012;154(7):1119-1126.

3. Chourdia V. Elongated Styloid Process (Eagle's Syndrome) \& Severe Headache. Indian J Otolaryngol Head Neck Surg. 2002;54(3):238-241. 
4. Ozdemir MB, Okunak M, Koseler A, et al. An ancient anatomic variation: bilateral elongated styloid process of cranium. Ital J Anat Embryol. 2013;118(2):184-188.

5. Basekim CC, Mutlu H, Gungor A, et al. Evaluation of styloid process by three-dimensional computed tomography. Eur Radiol. 2005;15(1):134-139.

6. Reddy RS, Kiran CS, Madhavi NS, et al. Prevalence of elongation and calcification patterns of styloid process in south India. J Clin Exp Dent. 2013;5(1):e30-e35

7. Bozkir MG, Boga H, Dere F. The Evaluation of Elongated Styloid Process in Panoramic Radiographs in Edentulous Patients. Turkish Journal of Medical Sciences. 1999;29:481-485.

8. Gozil R, Yener N, Calguner E, et al. Morphological characteristics of styloid process evaluated by computerized axial tomography. Ann Anat. 2001;183(6):527-535.

9. Ramadan SU, Gokharman D, Tuncbilek I, et al. Assessment of the stylohoid chain by 3D-CT. Surg Radiol Anat. 2007;29(7):583-588.

10. Oztas B, Orhan K. Investigation of the incidence of stylohyoid ligament calcifications with panoramic radiographs. J Investig Clin Dent. 2012;3(1):30-35.

11. Langlais RP, Langland OE, Nortje CJ. Diagnostic imaging of the jaws. Williams \& Wilkins, Baltimore, USA; 1995:661.
12. Guimaraes SMR, Carvalho ACP, Guimaraes JP, et al. Prevalence of morphological alterations of the styloid process in patients with temporomandibular joint disorder. Radiol Bras. 2006;39(6):407-411.

13. Ilguy D, Ilguy M, Fisekcioglu E, et al. Assessment of the stylohyoid complex with cone beam computed tomography. Iran J Radiol. 2012;10(1):21-26.

14. de Andrade KM, Rodrigues CA, Watanabe PC. Styloid process elongation and calcification in subjects with TMD: clinical and radiographic aspects. Braz Dent J. 2012;23(4):443-450.

15. Keur JJ, Campbell JP, McCarthy JF, et al. The clinical significance of the elongated styloid process. Oral Surg Oral Med Oral Pathol. 1986;61(4):399-404.

16. Aral IL, Karaca I, Gungor N. Eagle's syndrome masquerading as pain of dental origin. Case report. Aust Dent J. 1997;42(1):18-19.

17. Petrovic B, Radak D, Kostic V, et al. Styloid syndrome: a review of literature. Srp Arh Celok Lek. 2008;136(11-12):667-674.

18. Sandoval GP, Villamizar JR, Castillo CE, et al. Proceso estiloideo elongado y sindrome de Eagle. Acta Otorrinolaringol Cir Cabeza Cuello. 2001;29:171-177. 